and people on the fringe of computing. The 20 essays in this fin de siècle collection have been seamlessly edited, and only three or four of the papers are evident pot-boilers.

The book is divided into three parts, dealing respectively with technology, computing and human identity, and business and economic issues. Of the six chapters in the technology stream, one of the highlights is an essay by Mark Weiser and John Seely Brown, both senior researchers at the famous Xerox PARC in Palo Alto, California. In the 1970s PARC researchers came up with the graphical user interface that 15 years later, as Microsoft Windows, made Bill Gates's fortune. Now workers at PARC have moved on to what they call "calm technology" - when computers become invisible and disappear into the woodwork. They foresee "clocks that find out the correct time after a power failure, kids' toys that are ever-refreshed with new software and vocabularies, paint that cleans off dust and notifies you of intruders, and walls that selectively dampen sounds." Got all that, Bill?

The first of the six essays on computers and human identity is by the eminent social researcher Sherry Turkle, who reflects on what it means for kids to grow up in a culture of video games and simulation. "Fifty years ago," she reminds us, "a child's world was full of things that could be understood in simple, mechanical ways. A bicycle could be understood in terms of its pedals and gears and a wind-up car in terms of its clockwork springs.” But lever the back off a Gameboy, and the child is confronted by an impenetrable chip. Thus children are led to psychological rather than mechanical explanations of their playthings; in effect, they perceive machines as having a kind of inner life "more alive than a car, but less alive than a bacterium".

Another essayist on computers and human identity is Terry Winograd, once enfant terrible of artificial intelligence, but now with his feet planted firmly on the floor. His essay touches on the vexed issue of the boundaries of computer science. Today there are terrific tensions and frustrations in computing research because a researcher on interface design probably has more in common with social psychologists on the other side of the campus than with the computer theoreticians in the same building. Winograd supposes that there may eventually be a split between interface designers and computer scientists, rather like the complementary roles of architect and civil engineer.

The final set of essays deals with economic and business issues. I think everyone will take away from this book a particular vision that captures their imagination above the others. For me it was an essay on "Information Warfare" by Larry Druffel, former director of the Software Engineering Institute. We have all picked up the idea, from the popular science press or voices in the air, that a new form of warfare is on the horizon. In this new blitzkrieg, taking out the enemy's information systems has the potential to do vastly more damage than the physical destruction caused by Second World War bombers. What would these weapons look like? One example Druffel cites is that of a 'rogue' program that floods the networks with bogus messages, impeding the free flow of information. The more advanced the economy, the greater the potential for devastation. Take out Albania's information systems and it probably wouldn't notice for three weeks. But do the same for the United States, 20 years down the road when it is totally dependent on the Internet, and the consequences would be awesome.

On a more upbeat note comes the delightful essay "There and Not There" by William Mitchell, the architect and cultural critic from the Massachusetts Institute of Technology, and Oliver Strimple, director of the Computer Museum in Boston. They ask why would anyone ever go out when everything they might want to see is on-line? In this articulate and optimistic essay, the authors persuasively argue that telepresence is no substitute for 'being there'. Television or a Web-browser simply cannot capture the full experience of going to a live pop concert, theatre performance, art gallery or soccer match. That indefinable, emotional something one gets at the real event they call 'aura'. We all knew it in our hearts, but they have given us a word for it.

Martin Campbell-Kelly is in the Department of Computer Science, University of Warwick,

Coventry CV4 7AL, UK.

\section{Incomplete theorems}

\section{What is Mathematics, Really?}

by Reuben Hersh

Oxford University Press/Cape: 1997. Pp. 343. $\$ 35, £ 18.99$

\section{Ivar Ekeland}

The title poses quite a question, and adding the word 'really' does not make it any easier. Empty words will not do: hard definitions are required. So what does 'really' really mean here?

It could mean: "What is modern mathematics, what makes it important in - or irrelevant to - our everyday life, what is it like to be an active mathematician?" There is much to say here. There has been an exponential growth in the number of scholars, books, journals, papers and theorems produced in the past century. Whole fields, such as probability theory, functional and numerical analysis, and noncommutative geometry, have been created. Older fields, such as algebraic

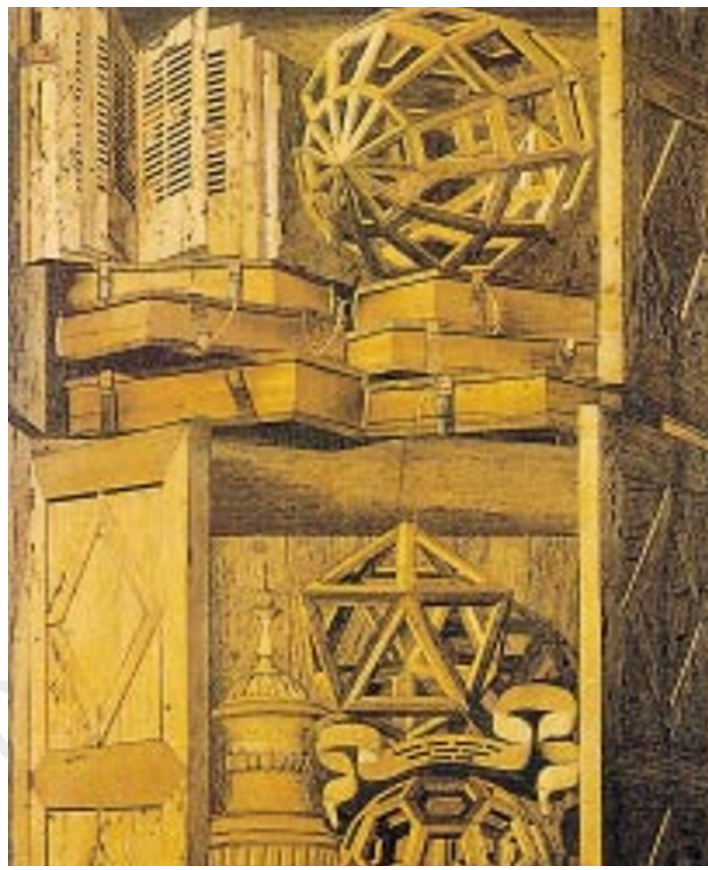

Facets of history: details of a wooden tarsia in the church of Santa Maria in Organo, Verona, Italy. From Polyhedra by Peter R. Cromwell

(Cambridge University Press, $\mathfrak{E} 30, \$ 44.95$ ).

geometry or number theory, have enjoyed tremendous progress, the solution of Fermat's last theorem being a case in point. The use of mathematics has become pervasive in engineering for filtering noisy signals and controlling processes, as well as in economics or finance, as shown by the success of the Black-Scholes model for pricing derivative securities.

It could also mean: "What is the inner meaning of mathematics?" Is there anything more to mathematics than its outward success story? Is it an activity to be pursued for its own sake, independently of material rewards? Painters or writers are supposed to be aiming for timeless achievement in art, not for recognition among their contemporaries, which may not even come during their lifetime. Is it the same with mathematicians? Are they artists in their own way? And, if so, what kind of art is theirs?

Strangely enough, this book goes neither way. It describes nothing of modern mathematics, except for a discussion about the foundations of mathematics and its connection with logic, which is far from the preoccupations of most working mathematicians. There is nothing at all to suggest the breadth and scope of mathematics today, or how much it has changed in the past century. It is always annoying to see the same tired, age-old examples crop up again and again: how to prove that the square root of two is irrational, how to use the tools of differentiation to exploit Galileo's law of falling bodies, and so on.

The book fails also to answer the question about the nature of mathematics. It dismisses it as "futile", leaving to forthcoming progress 
in the neurosciences whatever kind of answer is possible. To quote the author: "How does mathematics come about, in a daily, down-toearth sense? That question belongs to psychology, to the history of thought, and to other disciplines of empirical science. It can't be answered with philosophy."

So what does the author do? He presents his own philosophy of mathematics, which is now a fairly easy thing, considering all the questions he has decided such a philosophy should not answer. This philosophy he calls "humanism". The basic principle is: "A world of ideas exists, created by human beings, existing in their shared consciousness. These ideas have objective properties, in the same sense that material objects have objective properties. The construction of proof and counterexample is the method of discovering the properties of these ideas. This branch of knowledge is called mathematics."

I find it hard to understand what is meant by "shared consciousness" and to see how ideas could have "objective properties" in the "same sense" that material objects do. If I ventured such views in public, I would certainly try to clarify them, referring to such sciences as linguistics (after all, shared consciousness, whatever it is, must be mediated through language, and Chomsky has gone a long way towards a scientific analysis of the phenomenon) or to history (does a historical fact share the same objective properties as an experimental fact in physics?). Here, of course, such preoccupations are dismissed as "futile", so the author can take his "philosophy" for granted and proceed without further ado.

In the first part of the book, the author develops the ideas that "mathematics is human. It's part of and fits into human culture" and that "mathematics knowledge isn't infallible. Like science, mathematics can advance by making mistakes, correcting and recorrecting them." He contrasts these (very reasonable) ideas with a Platonist approach, which would take the stand that mathematics already 'exists' somewhere (written down in God's great book), so that theorems are discovered (unveiled), and not created, by humans. Mathematicians are then divided into humanists and Platonists, and the second part of the book is devoted to a review of prominent mathematicians through the ages, classified according to the stand they have taken on this question. At the end, their political opinions are reviewed as well, and, not surprisingly, even with the help of some elementary statistics, Platonists are found to be mostly conservative-righties whereas humanists are mostly democrat-lefties.

As a source of information about mathematics in general, the book is a failure. There remains scattered information, mostly in the form of quotations, about the foundations debate in mathematics. And the author does give unexpected entertainment at times. It is difficult to keep a straight face while reading that Pythagoras, for instance, for whom no biographical data are available, except the facts that he lived in the sixth century $\mathrm{BC}$ and that none of his writings survive, was a 'rightie'. There is also some humour in seeing that the author, presumably wishing to spare the critics time and trouble, concludes his book with a "self-graded report card". The result: "Could be worse." Of course.

Ivar Ekeland is at the Ceremade et Institut de

Finance, Université Paris-Dauphine, 75775 Paris

Cedex 15, France.

\section{O brave new world that has Prozac in't!}

\section{Britain on the Couch: Why We're Unhappier Compared With 1950 Despite Being Richer - A Treatment for the Low-Serotonin Society}

by Oliver James

Century: 1997. Pp. 402. £16.99

\section{Chris McManus}

Two subtitles maketh a reviewer's job easier. And should one miss the quasi-eighteenthcentury prolixity of the title page, the opening lines also summarize the argument: "The premise of this book is that we are unhappier compared with $1950 . .$. that people who are unhappy tend to have low levels of serotonin and that levels thereof are largely caused by our social psychological environment."

Then follows a rambling mishmash of reviews of published research (always with hundreds of studies, thousands of subjects and unanimity of scientific interpretation), supplemented by case-histories from the author's experience, or his television documentaries, or secondary analysis of dysfunctionality in the British royal family. Only the latter, coupled with refreshing references to British rather than US television, justifies "Britain" in the title. As worldwide sales must be reduced, and the scientific evidence is international, I wondered about parallel editions for other countries - say, Albania on the Couch, detailing dysfunctionality in King Zog's descendants?

James's main argument is that we ("This book is about... people like us") are now more

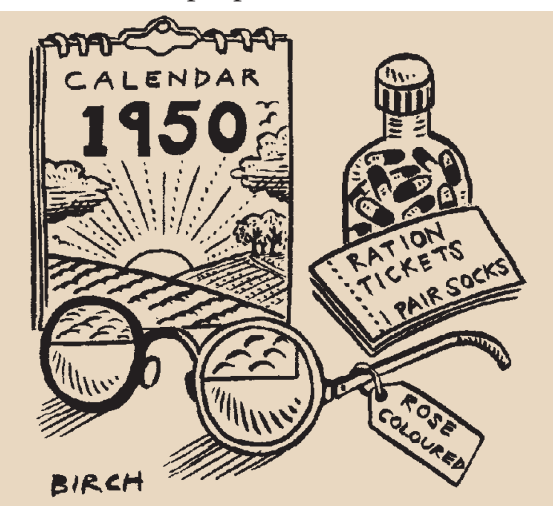

depressed (as well as anxious, phobic, obsessional, anorectic, bulimic, gambling-addicted, violent, paranoid, alcoholic, drug-hooked and sexually promiscuous) than in 1950, the common denominator being reduced brain serotonin (present mainly as metaphor rather than molecule). Society has changed since 1950, becoming more competitive, less certain and less predictable. We know more about other people, and compare ourselves more, often with high-profile media-inflated role models, and find ourselves wanting. And a war between the sexes ("gender rancour" in James's quaint phrase), with less well-defined roles, increases divorce and disrupts childhood. This potent mixture makes naked apes, recently out of Africa, more depressed (and anxious, and so on). Is this plausible?

The book's argument depends critically on depression being more common now than half a century ago. Two other current controversies indicate the methodological problems. Is childhood asthma truly increasing, or is there just increased willingness to report symptoms or make diagnoses? Has intelligence really increased this century (scores on identical tests are certainly higher), or is there just increased impulsivity, test-wiseness, guessing or visual literacy?

For psychiatry the problems are much greater. Standardized instruments such as the General Health Questionnaire now routinely use higher cut-offs for 'caseness', as people more willingly acknowledge problems. Historical studies of depression have not used equivalent criteria. James's brief appendix on "the scientific evidence" depends almost entirely on retrospective self-diagnoses in Klerman's controversial study of subjects of different ages. Even if depression has increased, proving causation is even more problematic; we see what we want to see, particularly when social and political factors are involved.

The final chapters give James's prescriptions for raising our low serotonin levels. Twenty million of the UK population would benefit from that contemporary soma Prozac (despite the claimed low libido, erectile failure or anorgasmia in 30-70 per cent of users). Psychotherapy and a more collectivist, communitarian "advanced capitalism" would also help.

Neither is diet neglected, with a serotoninboosting recipe reminiscent of George Bernard Shaw's crankiness: "One approach is to consume only the juice extracted from pears, sweet beetroot... and carrots, from a juice extractor for a period of three days every month, consuming as many apples as are required if hungry in the interim." Surpisingly, James — unlike G. B. S. — doesn't tell us to stimulate the phagocytes.

Chris McManus is at the Centre for Health Informatics and Multiprofessional Education, University College London Medical School, Whittington Hospital, London N19 5NF, UK. 